\title{
$\nabla$ Clinical and Microbiological Profile of Diabetic Foot
Infections in Inpatients at a Tertiary Care Hospital
}

\section{IJCRR}

Section: Healthcare

ISI Impact Factor

(2019-20): 1.628

IC Value (2019): 90.81

$\operatorname{SJIF}(2020)=7.893$

(c) (i) (8)

Copyright@IJCRR

\section{Dhanaleha P1, Anand MR², Jayapradha S ${ }^{3}$, Abarna $\mathbf{V}^{4}$}

'Assistant Professor, Department of Microbiology, Sri Lakshminarayana Institute of Medical Sciences (SLIMS), Puducherry, India;

${ }^{2}$ Assistant Professor, Department of Orthopaedics, Govt. Thiruvarur Medical College, Thiruvarur, Tamil Nadu, India; ${ }^{3}$ Professor,

Department of Microbiology, Sri Lakshminarayana Institute of Medical Sciences, Puducherry, India.

\section{ABSTRACT}

Introduction: Chronic foot infections in patients with diabetes mellitus are a common and difficult problem. The optimal management of these diabetic foot infections requires isolation and identification of the various pathogens and selection of appropriate antibiotic therapy according to the sensitivity patterns.

Aims and Objectives: To determine the prevalence of various bacterial pathogens in diabetic foot infections (DFIs).

Materials and Methods: A retrospective analysis of the culture of bacterial isolates of pus, pus swabs and tissue samples obtained from diabetic patients admitted in surgical wards at SLIMS, were carried out over 4 years from August 2016 to September 2020.

Results: Total growth constituted 131(95\%) monomicrobial growth was 107 (78\%) and polymicrobial growth was 24(17.5\%). In our study, Gram-negative isolates were 77 (79\%) with Pseudomonas spp being the most predominant. Most of the Gram-negative bacteria were found to be sensitive to amikacin (56.9\%), imipenem (66.6\%) and piperacillin-tazobactam (47.1\%). Grampositive isolates were $11(11.3 \%)$ with Staphylococcus aureus being the most predominant. In our study Gram, positive isolates were sensitive to erythromycin (81.8\%), ciprofloxacin $(81.8 \%)$ and cotrimoxazole $(54.5 \%) .100 \%$ sensitivity was observed with linezolid, teicoplanin and vancomycin. A total of $21(27.3 \%)$ patients who presented with gangrene were amputated.

Conclusion: There is an increase in the prevalence of organisms as Wagner's grade increased with Gram-negative growth being more predominant. Frequent surveillance of antibiotic-resistant patterns would be useful for deciding empiric antibiotic therapy.

Key Words: Clinical and microbiological profile, Diabetic foot infections (DFI), Polymicrobial, Retrospective study, Sensitivity pattern, Wagner's Grading

\section{INTRODUCTION}

Chronic foot infections in patients with diabetes mellitus are common and difficult to treat. Diabetic individuals have at least a 10-fold greater risk of being hospitalized for soft tissue infections of the foot than normal individuals. The diabetic population in India will be expected to increase to 57 million in $2025 .{ }^{1}$ The subcutaneous wounds have a likely chance of spreading into deeper tissues thus resulting in complications like gangrenous changes and amputations. ${ }^{3}$ They usually complicate the initially uninfected ulcerations that follow minor trauma in patients with neuropathy resulting in chronic neuropathic ulcers and tissue necrosis or osteomyelitis with draining sinus.
Infection plays a major role in the development of moist gangrene. Pseudomonas spp, Enterococcus spp and Proteus spp are organisms which are responsible for extensive tissue destruction as there is poor blood circulation of the foot.

The optimal management of these diabetic foot infections requires isolation and identification of the various pathogens and selection of appropriate antibiotic therapy according to the sensitivity patterns. A retrospective study is carried out to find out the various bacterial pathogens in diabetic foot infections and their impact on the outcome of the patients.

Aims and Objectives: To determine the prevalence of various bacterial pathogens in diabetic foot infections (DFIs) and their susceptibility to antimicrobial agents. To investigate the

\section{Corresponding Author:}

Dr. Dhanaleha P, Assistant Professor, Department of Microbiology, Sri Lakshminarayana Institute of Medical Sciences (SLIMS), Puducherry, India; Mob: 9994196203; Email: danasamy1@gmail.com

ISSN: 2231-2196 (Print)

Received: 30.01 .2021
ISSN: 0975-5241 (Online)

Revised: 05.02 .2021
Accepted: 19.04 .2021

Published: 12.09 .2021 
microbiological profiles of DFIs concerning different grades of Wagner classification and outcome for DFIs.

\section{MATERIALS AND METHODS}

A retrospective analysis of bacterial isolates from pus, pus swabs and tissue samples from diabetic patients admitted for surgical care was done covering a period of 4 years from August 2016 to September 2020. Processing of the samples for culture, bacterial identification and antimicrobial susceptibility pattern was done as per standard procedures. ${ }^{2} \mathrm{~A}$ record of all samples received, details of the organism isolated along with its antibiotic sensitivity pattern for the first line and second-line agents are being maintained in the Microbiology laboratory analysis of grading of ulcers, risk factors and outcome of patients will be done from the records maintained in Medical Records Department. The results are represented in percentages.

\section{RESULTS}

In this study among 137patients with DFI, 108 were male and 29 were female, the mean age distribution is 61-70 years. Total growth constituted 131(95\%) monomicrobial growth was $107(78 \%)$ and polymicrobial growth was $24(17.5 \%)$. The distribution of bacterial isolates according to Wagner's grades were $10.3 \%$ in me, $14.4 \%$ in II, $25.7 \%$ in III, $24.7 \%$ in IV and $24.7 \%$ in V(Table1, Fig1). In our study, Gramnegative isolates were 77 (79\%) with Pseudomonas spp being the most predominant. Most of the Gram-negative bacteria were found to be sensitive to amikacin $(56.9 \%)$, imipenem $(66.6 \%)$ and piperacillin-tazobactam $(47.1 \%)$ (Fig 2,3). Gram-positive isolates were 11 (11.3\%) with Staphylococccus aureus being the most predominant. MRSAbeing $5.1 \%$. In our study Gram-positive isolates were sensitive to erythromycin (81.8\%), ciprofloxacin $(81.8 \%)$ and cotrimoxazole (54.5\%) (Fig 4).100\%sensitivity was observed with linezolid, teicoplanin and vancomycin. A total of 21 (27.3\%) patients who presented with gangrene were amputated. The level of amputation ranged from toes $(\mathrm{n}=16)$ to below-knee $(n=5)$. Empirical antibiotics used in these patients were thirdgeneration cephalosporins.

\section{DISCUSSION}

In this study, males were more predominant than females, with the mean age distribution being 61-70 years which corresponds to a retrospective study in DFI patients conducted by Mc Donald et al. ${ }^{3}$

In the present study among 137 patients with DFI, monomicrobial growth was $107(78 \%)$ and polymicrobial growth was
$24(17.5 \%)$, which is similar to the study conducted by Hadadi. ${ }^{4}$

Mohd Zubai, ${ }^{5}$ Anandi, ${ }^{6}$ Ramakant, ${ }^{7}$ Pappu $\quad \mathrm{K},{ }^{8} \quad$ and Citron, ${ }^{9}$ have reported $56.6 \%, 19 \%, 23 \%, 92 \%$ and $16.2 \%$ monomicrobial infections and 33\%, 67\%, 66\%, 7.7\% and 83 $\%$ of polymicrobial infections respectively.

The distribution of bacterial isolates according to Wagner's grades were $10.3 \%$ in me, $14.4 \%$ in II, $25.7 \%$ in III, $24.7 \%$ in IV and $24.7 \%$ in V, which coincides with the study conducted by Mahmoud B.Ahmedwhere bacterial growth was predominant in grade IV and $\mathrm{V} .{ }^{10}$

In our study, Gram-negative isolates were $77(79 \%)$ with Pseudomonas spp being the most predominant (26.8\%), followed by Escherichia coli (12.3\%), which is in concordance with findings of Bansal and Jayashree Kona which is $76 \%$ and $72.36 \%$ respectively with Pseudomonas aeruginosa being predominant. ${ }^{11,12}$ Zubair and Hadadireported Escherichia coli $(26.6 \%)$ and $28 \%$ which is lower in the present study. ${ }^{5,4}$ Goh et aland Hadadireported Pseudomonas $18 \%$ and $8 \%{ }^{13,4}$

Gram-negative bacteria were found to be sensitive to amikacin $(56.9 \%)$, imipenem $(66.6 \%)$ and piperacillin-tazobactam (47.1\%). Bansalobserved $100 \%$ sensitivity to imipenem, $96 \%$ to piperacillin-tazobactam and $90 \%$ to Amikacin similarly Mahmoud B.Ahmedobserved sensitivity of $98.3 \%$ to imipenem and $89.8 \%$ to amikacin which is much higher when compared to the present study. ${ }^{11,10}$

Gram-positive isolates were 21\% with Staphylococcus aureus $(11.3 \%)$ being the most predominant whereas MRSA being $5.1 \%$. This is similar to the study conducted by Bansal. ${ }^{11}$ Alavireported a single microorganism, mainly Staphylococcus aureus, as the most frequently isolated bacteria from diabetic foot patients. ${ }^{14}$ Whereas Macdonald et al also reported higher distribution of Staphylococcus au$\operatorname{reus}(32.5 \%)$ among Gram-positive organisms. ${ }^{3} \mathrm{Global}$ prevalence of MRSA is found to be $15-30 \%$ but in our study, it is much lower. ${ }^{16,17}$ In our study Gram-positive isolates were sensitive to erythromycin (81.8\%), ciprofloxacin $(81.8 \%)$ and cotrimoxazole (54.5\%). ${ }^{3}$ Alva observed cotrimoxazole to be $53.8 \%$ and ciprofloxacin to be $58.3 \%$ which is similar to the present study. ${ }^{18} 100 \%$ sensitivity was observed with vancomycin, teicoplanin and linezolid which is similar to studies by M.B Girish and Jayashree Konar. ${ }^{15,12}$

A total of 21 (27.3\%) patients who presented with gangrene were amputated. The level of amputation ranged from toes $(n=16)$ to below-knee $(n=5)$. Hadadi and Alva reported $45.5 \%$ and $34.4 \%$ amputations in their studies. ${ }^{4,1}$ Empirical antibiotics used in these patients were third-generation cephalosporins. Treatment initiation with broad-spectrum antimicrobials including carbapenems and piperacillin-tazobactam for more extensive chronic moderate and severe infections is 
a safety measure as suggested by a study. ${ }^{19}$ However definitive treatment should be initiated following antibiogram and clinical correlation. In deeper infections surgical as well as medical intervention is necessary management of DFIs.

\section{CONCLUSION}

There was an increase in the prevalence of bacteria as the Wagner's grade increased with Gram-negative growth being more predominant. Frequent surveillance of antibiotic resistance patterns would be useful in deciding empiric antibiotic therapy.

Further, the findings of this study emphasize the need to select the antimicrobial treatment which should be guided by proven culture results and antimicrobial sensitivity patterns exhibited by isolates.

\section{ACKNOWLEDGEMENT}

The authors acknowledge the immense help received from the scholars whose articles are cited and included in references to this manuscript. The authors are also grateful to authors/editors/publishers of all those articles, journals and books from where the literature for this article has been reviewed and discussed."

Conflict of Interest: There is no conflict of interest.

Source of Funding: No funding has been received for this study.

\section{Authors' Contribution}

Dr. Dhanaleha P: Clinical Study

Dr Jayapradha.S: Study Design, Literature Review

Dr Aparna V: Manuscript preparationDr Anand M.R: Manuscript editing

Ethical Clearance: Obtained from the SLIMS NO.IEC/C$\mathrm{P} / 04 / 2020$ dated 30.10 .20

\section{REFERENCES}

1. Alva KA, Aithala PS, Rai R, Rekha B. Clinical and microbiological profile of diabetic foot in patients admitted at a tertiary care centre in Mangalore. Muller J Med Sci Res. 2013;4:3-7.
2. Clinical Laboratory Standards Institute (CLSI) Performance Standards for Antimicrobial Susceptibility Testing Eighteenth informational supplement: M-100-S-2008,18: 28.

3. Macdonald, K.E., Jordan, C.Y., Crichton, E. et al. A retrospective analysis of the microbiology of diabetic foot infections at a Scottish tertiary hospital. BMC Infect Dis 20, 218 (2020). https://doi.org/10.1186/s12879-020-4923-1

4. Hadadi A, Omdeh Ghiasi H, Hajiabdolbaghi M, Zandekarimi M, Hamidian R. Diabetic foot: infections and outcomes in Iranian admitted patients. Jundishapur J Microbiol. 2014 Jul;7(7):e11680. doi: 10.5812/jjm.11680. Epub 2014 Jul 1. PMID: 25368803; PMCID: PMC4216583.

5. Zubair M, Malik A, Ahmad J. Clinico-bacteriology and risk factors for the diabetic foot infection with multidrug-resistant microorganisms in North India. Biol Med. 2010;2(4):22-34.

6. Anandi C, Alaguraja D, Natarajan V. Bacteriology of diabetic foot lesions. Indian J Med Microbiol. 2004;22(3):175-78.

7. Ramakant P, Verma AK, Misra R, Prasad KN. Changing Microbiological profile of pathogenic bacteria in diabetic foot infections: time to rethink on which empirical therapy to choose? Diabetologica. 2011;54(1):58-64.

8. Pappu AK, Sinha A, Johnson A. Microbiological profile of diabetic foot ulcer. Calicut Med Journal. 2011;9(3):e1-4.

9. Citron DM, Goldstein EJC, Merriam VC, Lipsky BA. Bacteriology of moderate to severe diabetic foot infections and in-vitro activity of antimicrobial agents. J Clin Microbiol. 2007;45(9):2819-28.

10. Mahamoud BA, Al-Mallah I, Said Eissa AN, Asif JF, Eed ME, Infection in the diabetic foot, Menoufia Medical Journal 2013,26:49-53.

11. Bansal E, Garg A, Bhatia S, Attri AK, Chander J. Spectrum of microbial flora in diabetic foot ulcers. Indian J Pathol Microbiol 2008;51:204-8

12. Jayashree K, Sanjeev D. "Bacteriological profile of diabetic foot ulcers, with a special reference to antibiogram in a tertiary care hospital in eastern India". JEMDS 2013; (2)48,9323-9328

13. Goh, TC, Bajuri MY, Nadarajah C, et al. Clinical and bacteriological profile of diabetic foot infections in tertiary care. J Foot Ankle Res 13, 36 (2020).

14. Alavi A, Sanjari M, Haghdoost A, Sibbald RG. Common foot examination features of 247 Iranian patients with diabetes. Int Wound J. 2009;6(2):117-22

15. Girish MB, Kumar TN, Srinivas R. Pattern of antimicrobials used to treat infected diabetic foot in a tertiary care hospital in Kolar. Int J Pharm Biomed Res. 2010;1(2):48-52.

16. Eleftheriadou I, Tentolouris N, Ariana V, Jude E, Boulton AJ. Methicillin-resistant Staphylococcus aureus in diabetic foot infections. Drugs. 2010;70(14):1785-97.

17. Stacey HJ, Clements CS, Welburn SC, Jones JD. The prevalence of methicillin-resistant Staphylococcus aureus among diabetic patients: a meta-analysis. Acta Diabetol. 2019;56:907-21.

18. Alva K A, Aithala P S, Rai R, Rekha B. Clinical and microbiological profile of diabetic foot in patients admitted at a tertiary care centre in Mangalore. Muller J Med Sci Res 2013;4:3-7

19. Bajuri MY, Abdul Razak KA. Chronic osteomyelitis of the femur with a segmental bone defect: concepts and treatment. J Krishna Inst Med SciUniv. 2017;6(2):127-30. 
Table 1: Distribution of bacterial isolates from various grades of diabetic foot infections.

\begin{tabular}{|c|c|c|c|c|c|c|c|}
\hline Organism & Grade 1 & Grade 2 & Grade 3 & Grade 4 & Grade 5 & Total & $\% \%$ \\
\hline Gram negative bacilli & & & & & & 77 & 79 \\
\hline E.coli & & 2 & 3 & 3 & 4 & 12 & 12.3 \\
\hline Klebsiella spp & 1 & 2 & 2 & 4 & 2 & 11 & 11.3 \\
\hline Enterobacter & & & & 2 & 2 & 4 & 4.1 \\
\hline Proteus spp & & 4 & 2 & 3 & 4 & 13 & 13.4 \\
\hline Pseudomonas spp & 6 & 4 & 5 & 2 & 9 & 26 & 26.8 \\
\hline NFGNB & 1 & 1 & 2 & & 2 & 6 & 6.2 \\
\hline Acinetobacter spp & & & 5 & & & 5 & 5.1 \\
\hline Gram-positive cocci & & & & & & 20 & 21 \\
\hline Staphylococcus aureus & 2 & & 3 & 5 & 1 & 11 & 11.3 \\
\hline MRSA & & 1 & 1 & 3 & & 5 & 5.1 \\
\hline Streptococcus spp & & & 1 & 2 & & 3 & 3.1 \\
\hline Enterococcus spp & & & 1 & & & 1 & 1 \\
\hline & 10 & 14 & 25 & 24 & 24 & 97 & 100 \\
\hline
\end{tabular}

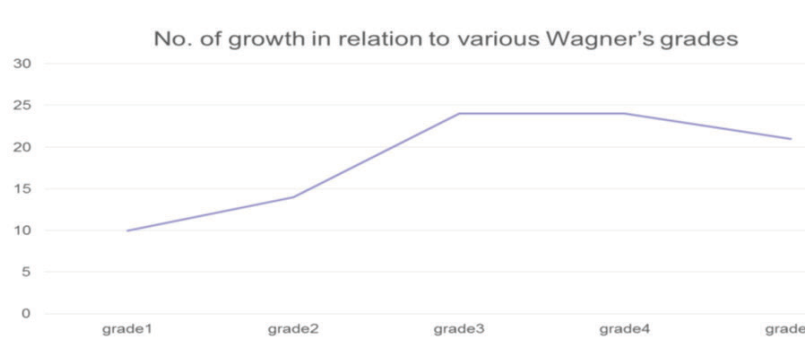

Figure 1

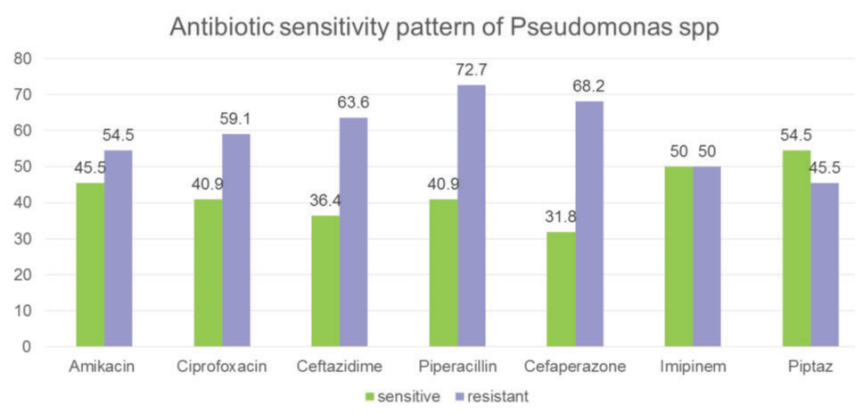

Figure 2

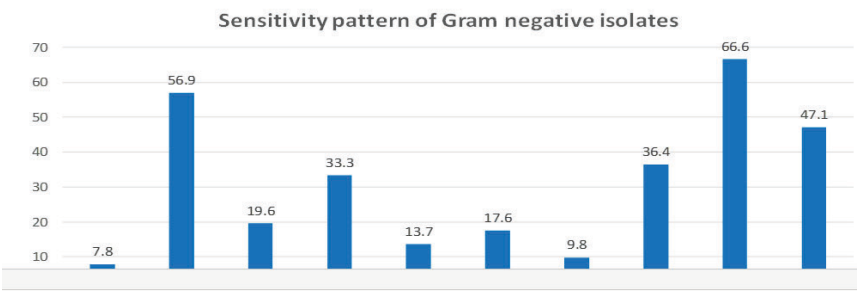

Figure 3

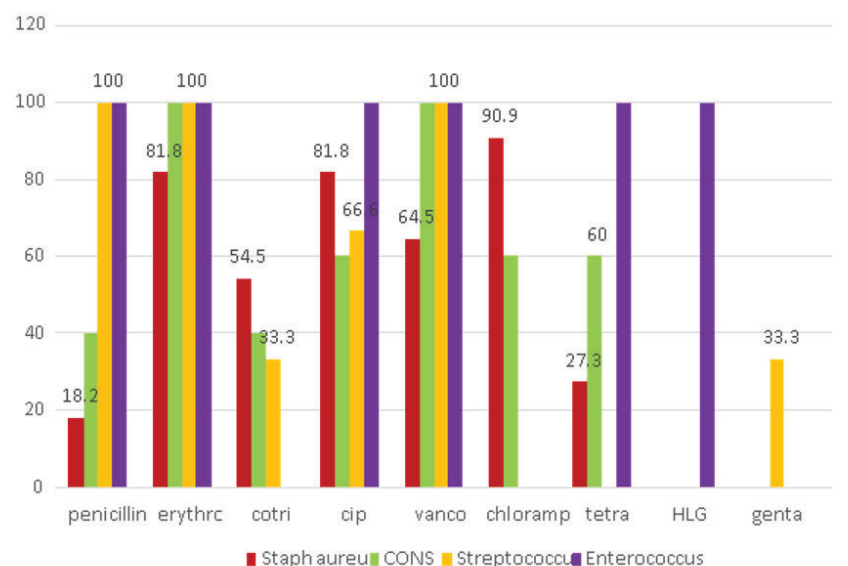

Figure 4: Sensitivity Pattern of Gram-positive cocci. 